\title{
2006-1237: A CONCEPTUAL MODEL FOR CAPSTONE ENGINEERING DESIGN PERFORMANCE AND ASSESSMENT
}

\section{Denny Davis, Washington State University}

Denny Davis is Professor of Bioengineering and Co-Director of the Engineering Education Research Center at Washington State University.

Steven Beyerlein, University of Idaho

Steven Beyerlein is Professorof Mechanical Engineering at the University of Idaho.

Olakunle Harrison, Tuskegee University

Olakunle Harrison is Associate Professor of Mechanical Engineering at Tuskegee University.

\section{Phillip Thompson, Seattle University}

Phillip Thompson is Associate Professor of Civil and Environmental Engineering at Seattle University

\section{Michael Trevisan, Washington State University}

Michael Trevisan is Professor of Educational Psychology and Director of the Assessment and Evaluation Center at Washington State University.

\section{Benjamin Mount, Washington State University}

Benjamin Mount is Research Assistant for the Engineering Education Research Center at Washington State University. 


\title{
A Conceptual Model for Capstone Engineering Design Performance and Assessment
}

\begin{abstract}
Assessment in capstone engineering design courses is vital to engineering education programs. The capstone design course is the climax of design education and often the context for much of the assessment done in engineering degree programs. Capstone design course instructors' admittedly low confidence for assessing student performance in these courses poses a crucial obstacle to the assessment process. A key issue is a lack of clear outcomes definition for engineering design and sound, defensible assessments for these outcomes. This paper draws from findings in design literature and from engineering design education experience to construct a conceptual model of engineering design that guides development of associated design learning outcomes and assessment of student achievements in design.

A conceptual model of design is vital to design education, because it is one of three essential cornerstones - model, observation, and interpretation - for constructing assessments ${ }^{1}$. In the context of an engineering classroom, design performance produces two different and complementary types of outcomes: learner development and solution development. Further, design is: open-ended, iterative, creative, collaborative, goal-driven, process-intensive, productfocused, customer-oriented, value-added, and constrained by society. Learner and solution development usually progresses from a state of students' fragmented understanding and ideas to a more mature state of integrated understanding and design solutions.

The proposed conceptual model for engineering design identifies four areas of performance that describe design: (1) personal capacity, (2) team processes, (3) solution requirements, and (4) solution assets. The first two characterize learner development and the latter two characterize solution development. Personal capacity is the designer's development of skills which support technically sound and responsible design. Team processes address a team's behaviors and productivity in design activities. Solution requirements address the team's understanding of stakeholder needs and concerns. Solution assets encompass the value added, practicality, and impact of the design solution. These four performance areas are essential to design. They identify performances that develop over time, contribute to the success of design outcomes, and stimulate growth in one another for integrated enhancement of design performance. They also provide the basis for a versatile, comprehensive definition of engineering design performance that can guide instruction and can focus assessments in capstone engineering design courses.
\end{abstract}




\section{Background}

\section{Design Assessment}

Engineering design has received increased attention in US engineering curricula as a tool for making engineering more attractive to students while also developing many of the practical skills needed for engineering practice. Design is considered by many to be the distinguishing feature of engineering and the motivating factor in the learning of engineering ${ }^{2}$. Design is promoted as the "cornerstone of engineering learning." Capstone design courses have increasingly used industry-sponsored projects that give students opportunities to address real problems ${ }^{3}$. Capstone design courses are also a site for developing many of the higher-level engineering learning outcomes and those requiring integration of knowledge. Over $90 \%$ of capstone design instructors assign great value to the capstone design course. Many believe their courses offer potential for achieving and assessing all of the engineering criterion 3 outcomes required by $\mathrm{ABET}^{4,5}$.

Variations in capstone engineering courses across the nation create challenges to developing transferable assessments for capstone engineering design courses. Accordingly, few assessments have been reported for measuring achievement of engineering design outcomes. The TIDEE Design Team Readiness Assessment (DTRA) is useful as a pre-assessment for capstone design ${ }^{6}$. Atman and colleagues have used verbal protocol analysis, concept diagrams, and interviews to distinguish levels of design performance for students and professionals ${ }^{7,8,9}$. Sobek has used design journals and attributes of design products to assess student performance in capstone design projects ${ }^{10,11}$. Brackin and Williams used student portfolios to assess team skills in a capstone design course ${ }^{12}$. A national survey of capstone engineering design instructors indicates that most instructors create and use assessments that are untested for reliability or validity; thus, they have little confidence in their assessments of student competence in design ${ }^{4}$.

\section{Design Model}

A conceptual model for knowledge and abilities is one of three legs of the Assessment Triangle, used as a basis for knowing what students know ${ }^{1}$. Therefore, creation of valid assessments for capstone engineering design courses requires such a model for engineering design. Design model development presented here is part of a National Science Foundation project entitled:

"Transferable Assessments for Capstone Engineering Design Courses". Project leadership from a diverse multi-institution and multidisciplinary team offers potential for producing a model that is transferable across widely varied capstone course environments.

Achievement targets in capstone engineering design courses must be stated clearly so that performance differences are measurable. According to the National Research Council, assessments are most effective when they are based on explicit, clearly conceptualized cognitive models of learning that reflect the most scientifically credible understanding of ways learners represent knowledge and develop expertise in the domain ${ }^{1}$. Learning targets may take the form of knowledge mastery, reasoning proficiency, skills, ability to create products, and dispositions ${ }^{13}$.

Learning outcomes identified for engineering design courses vary greatly: in some courses the focus is on design products, in others on student design methodologies. For capstone design courses, learning outcomes commonly identified include: the engineering design process, integrating design process with teamwork and communication to produce results, achieving ABET engineering criterion 3 outcomes, addressing business and societal issues, operating as a 
professional, and making reasoned decisions. Davis et al. identified five outcome types relevant to design: (1) competencies or meeting a standard, (2) movement or growth in skills, (3) insights gained from authentic experiences, (4) major accomplishments or products of note, and (5) highlevel performances that integrate different kinds of knowledge ${ }^{14}$.

A survey of engineering design textbooks and design literature shows that design process representations vary greatly. As summarized by Mosborg et al.:

"Engineering textbooks have traditionally introduced students to engineering design by way of a block diagram. Although these diagrams vary slightly from one textbook to the next, the iconic diagram encloses each stage of the process in a block and depicts flow through the stages using arrows, typically double-ended to signify iteration between phases." "9

Performance in design draws on skills from cognitive, social, and affective domains of knowledge. Design decision making is described as social and cognitive ${ }^{15}$. Sophistication in design is characterized by reflective thinking, iteration and rate of transitions, information gathered, communication, and capitalizing on opportunities $9,16,17,18,19,20,21,22,23$.

The quality of design products is also an indication of the designers' abilities to design. This causes many capstone design instructors using client-sponsored projects to ask clients to serve as experts who score how well students' design products satisfy client needs ${ }^{4,11}$. Sobek and Jain argue that the quality of the design product is at least as important as the design process in gauging students' design abilities. They state that client satisfaction is measured by product quality and the client's overall satisfaction with the project. They postulate that the product must meet design requirements, be feasibly implemented, show creativity, add value through simplicity, and create a positive overall impression. Bogusch et al. state that more experienced designers recognize a larger set of stakeholder needs to be satisfied by a design solution ${ }^{24}$.

The varied perspectives and model representations of design professionals leave design educators with elusive definitions of engineering design and design outcomes. The need remains for crisp yet inclusive definitions of design to guide classroom instruction and assessment of design performance.

\section{Goal and Objectives}

\section{Goal}

The goal of this paper is to present a research-based conceptual model for engineering design fitting a broad range of capstone engineering design courses. For the intended educational context, the model must encompass both learner development and solution development. It also must include performances that distinguish novice from expert and are suitable for guiding the development of assessments and instructional strategies for capstone engineering design courses.

\section{Objectives}

Specific objectives achieved in this paper include:

1. A definitive purpose for capstone engineering design courses, 
2. A conceptual model of engineering design with areas of performance that characterize learner and solution development in diverse capstone engineering design courses,

3. Performance factors that span desired performance in each area, and

4. Performance criteria that articulate performance expected in each area.

\section{Purpose of Capstone Design}

Capstone design courses exist almost universally in engineering baccalaureate degree programs. They are mandated by engineering accreditation requirements set by $\mathrm{ABET}$, the organization accrediting engineering programs in the United States. Based on ABET engineering criteria 3c and 4, students must:

(3c) Demonstrate an ability to design a system, component, or process to meet desired needs within realistic constraints such as economic, environmental, social, political, ethical, health and safety, manufacturability, and sustainability, and

(4) Be prepared for engineering practice through the curriculum culminating in a major design experience based on the knowledge and skills acquired in earlier course work and incorporating appropriate engineering standards and multiple realistic constraints. ${ }^{5}$

Student performance in capstone design courses is important for accreditation purposes and for monitoring students' higher-level abilities in engineering. It should be noted also that many capstone design courses seek to provide students learning experiences that simulate professional practice, which offers an opportunity for an authentic assessment environment that can make assessment results more valid ${ }^{25,13}$. Therefore, we present the following purpose statement for capstone design courses.

\section{Purpose Statement}

The purpose of the capstone engineering design course is to provide students authentic engineering design experiences:

(a) in which teams develop design products to meet specific needs while complying with technical, business, professional, and societal constraints, and

(b) by which students' design performance can be assessed with validity.

\section{Conceptual Model Development}

\section{Methodology}

The authors engaged a variety of experts and accessed a wide range of resources over a two-year period to define a conceptual model for design. A team of six consultants provided the authors greater access to national expertise on engineering design and assessment. The consultant team served as a focus group for identifying current research findings and for reviewing development of a conceptual model for design, among other responsibilities in the project.

As a first step, the authors used research literature and personal experience to draft a conceptual model $^{26}$. The consultant focus group convened for two days to review the initial model, propose 
revisions, and suggest additional background materials and resources. After author reviews of additional literature and subsequent model refinement, the focus group convened for a second round of review and revision. After further refinement by the authors, the model received additional input at a national gathering of design faculty in May 2005.

During its development, the authors sought to meet the following criteria for the design conceptual model:

1. Simple enough to be understood by students, faculty, and assessors,

2. Encompass elements of learner development and solution development vital to design,

3. Communicate the iterative and interactive nature of design, and

4. Focus on design performances that are observable for assessment purposes

\section{Conceptual Model of Design}

The conceptual model for engineering design encompasses both learner and solution development. It reflects effective use and ongoing development of the designers' knowledge and skills. It also produces design solutions that truly meet the needs of stakeholders, the understanding of which develops over time.

Four areas are selected to encompass the scope of design performances and to enable differentiation of novice from expert designer: personal capacity, team processes, solution requirements, and solution assets. These are defined in Table 1. Personal capacity focuses on individual skills crucial to design. Team processes describe ways in which teams function to achieve more than they could individually. Solution requirements state the team's understanding of their design goals and constraints. Solution assets are the final products of design that present stakeholders value and satisfaction. Each performance area is essential to successful design, and each provides opportunity for challenge and identifiable achievement.

Table 1: Definition and performance areas for engineering design conceptual model

Definition: Engineering design draws from nurtured personal abilities and team processes to enable creation of valuable engineering solutions that meet progressively refined understandings of stakeholder needs and constraints.

Performance Areas: Design is characterized by four areas of performance:

- Personal Capacity: Individuals performing and improving individual skills essential to engineering design

- Team Processes: Teams developing and implementing collective processes that support team productivity in design

- Solution Requirements: Definition of targeted design solution performance and features expected to satisfy stakeholder needs and constraints

- Solution Assets: Results from a design project that meet needs and deliver satisfaction and value to key project stakeholders 
The conceptual model for design is further explained by Figure 1. Each of the four areas of performance influences, and is influenced by, the other three areas. For example, personal capacity influences the validity and adequacy of solution requirements, affects quality of human resources available for team processes, and influences the quality of design solution assets. In turn, personal capacity gains from solution requirements and an increased customer-focus are driven by team processes toward greater social skill development, and gain feedback from solution assets regarding one's personal competence in design. In addition, solution assets drive solution requirements to be practical, and they motivate team processes to be more productive. In turn, the solution assets gain from team processes a wholeness representing broad team inputs, and receive from solution requirements an understanding that makes solution assets responsive to stakeholder needs. These four areas of design performance interact synergistically to provide a richness in engineering design performance that enhances development of both the learner and the solution.

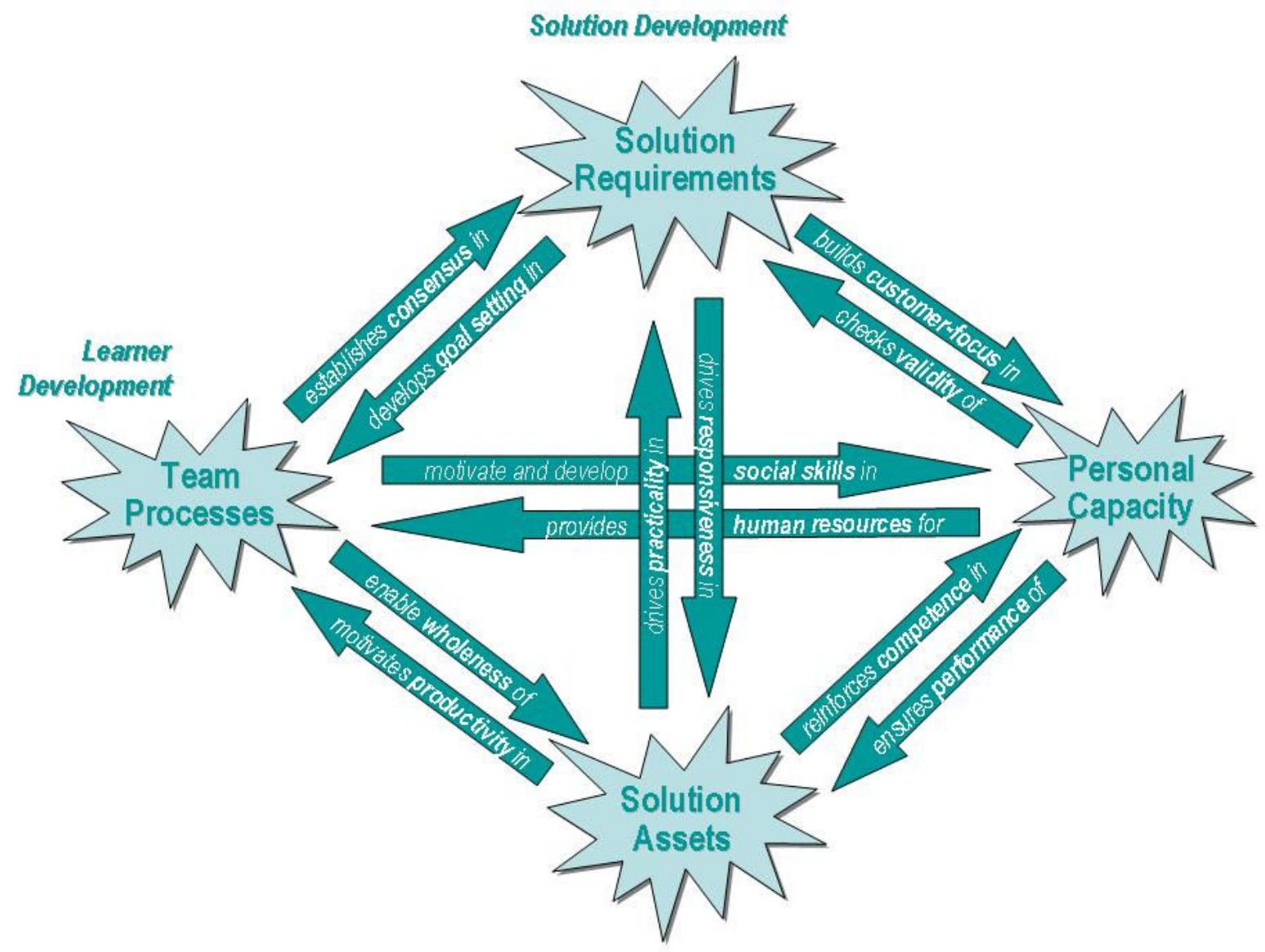

Figure 1: Design conceptual model performance areas and interactions 


\section{Capstone Design Course Model}

Capstone engineering design courses are important laboratories for student learning of design and venues for the assessment of design achievement. Design projects serve as a catalyst for learning in the course and as a source of evidence for a relatively authentic assessment performance. Students are challenged repeatedly to take control of their learning, think creatively, and to develop professional skills while completing their projects to the satisfaction of clients and the instructor. In reality, the course has two foci for development: learners and solutions.

Figure 2 illustrates developments of the learner and the solution that occur in parallel in a capstone engineering design course. Initially, students have limited knowledge and skills related to the project and their team. At this time, the project is also defined vaguely. Challenges occur immediately and repeatedly as students strive to develop their skills and knowledge while also producing a design solution of value to stakeholders. When seeking to make progress in the face of each challenge, students employ a variation of the basic design process ${ }^{27,28}$ to understand issues, define requirements, identify alternatives, make decisions, and implement their best resolution to the challenge. They use this same basic process to improve their personal capacity, team processes, solution requirements, and solution assets. Their final states in performance areas of personal capacity, team processes, solution requirements, and solution assets represent the fruits of their design project activity. Thus, examining achievements in these four performance areas becomes the focus for assessment in capstone engineering design courses.

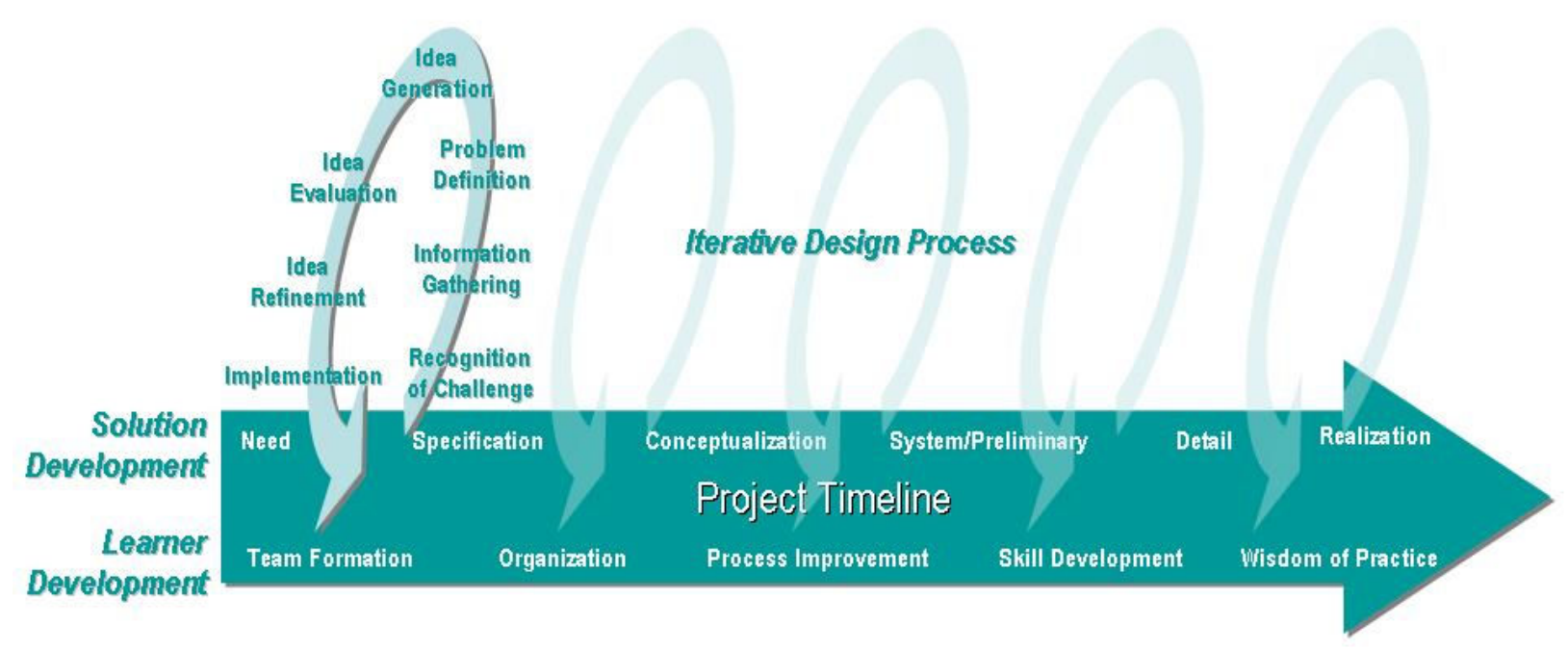

Figure 2: Conceptual model for capstone engineering design

\section{Performance Criteria}

Clear definitions of performance criteria enable instructors, students, and assessors to hold common performance expectations. In the sections below, performance criteria are derived to establish performance expectations for the four areas of the conceptual model for design. Table 2 presents a performance criterion statement for each area of design performance. Derivations of performance criteria are explained in paragraphs that follow. 
Table 2: Performance criteria for four areas of the conceptual model for design

$\begin{array}{ll}\text { Personal Capacity } & \begin{array}{l}\text { Individuals accomplish challenging goals related to design by employing } \\ \text { goal-driven initiative, competence in problem solving, integrity and } \\ \text { professionalism, and ongoing reflective development of their personal } \\ \text { abilities. }\end{array}\end{array}$

Team Processes The team achieves challenging goals in productivity and team function by strategic use of team resources, synergistic collaboration, decisions that add real value, and assessment-driven refinement of processes.

\section{Solution Requirements}

Solution Assets
Specifications reflect in-depth understanding of customer needs, business issues, state of the technology, and societal concerns about the solution, and provide clear targets for development of a valuable solution.

Design solutions meet or exceed expectations of stakeholders by delivering proven value in desired functionality, economic benefits, implementation feasibility, and favorable impacts on society.

Performance criteria statements were derived by:

1. Identifying performance factors or dimensions associated with the performance area,

2. Identifying performance qualities that characterize high levels of performance, and

3. Crafting a performance criterion statement to integrate qualities with factors.

Personal Capacity. A student's personal capacity is his or her ability to support design success as an individual. This includes their higher-level thinking and metacognition skills and their abilities to articulate understanding, connect domain knowledge to a need, and describe strategies for approaching problems ${ }^{16,17,18}$. It includes the ability to know when information is needed, to draw from previous knowledge, and to use tools effectively ${ }^{9}$. It must include the competent use of engineering fundamentals and independent learning ${ }^{29,30}$.

Performance in regard to personal capacity can be associated with four performance factors: achiever, analyst/problem solver, practitioner, and self-grower. An individual with personal capacity for design demonstrates an ability to achieve goals, analyze and solve problems, perform as a professional, and achieve independent personal growth. The achiever takes initiative, focuses effort, responds to change, and completes work. The problem solver selects appropriate methods, reasons effectively, applies tools well, and validates results. The engineering practitioner exhibits a service mindset, demonstrates integrity and respect for standards and norms, and takes responsibility in society. The self-grower self-assesses, plans, seeks needed resources, adjusts to change, and follows through for growth.

Quality in personal capacity is goal-driven and achieved by effective follow-through and ongoing learning. The performance criterion for personal capacity becomes: 
PeRSONAL CAPACITY: "Individuals accomplish challenging goals related to design by employing goal-driven initiative, competence in problem solving, integrity and professionalism, and ongoing reflective development of their personal abilities."

Team Processes. Team processes encompass the ways in which team members purposefully organize and work together to achieve team and individual goals related to their design project. Team processes include communication, teamwork, and team design processes , $28,29,30,31^{6}$. Communication in teams affects the quality of design activities ${ }^{22}$. More advanced designers spend more time in problem definition, gather information more frequently, iterate more frequently, and use iteration for greater value added ${ }^{18,19,21}$. Development of team and project management skills is prominent in design texts ${ }^{32,33}$.

Performance factors for team processes are: communicator/collaborator, manager/organizer, decision maker, and team-grower. That is, effective team processes for design will include effective communication and collaboration among members, organization and management of the project, strategic decision making, and advancement of team performance. Collaboration and communication require inclusion of others, valuing others' contributions, processing concerns among members, balancing member participation, processing information, and possessing collective goals. Management includes role/task assignment and review, leadership, accountability of members, and keeping project records. Effective decision making stems from clear decision criteria, exhibits creativity and synthesis of ideas, evaluates alternatives, allows for iteration, and produces action. Team growth embodies team self-assessment, reflection, learning from failures, and celebrating successes.

Quality in team processes requires ongoing process improvement driven by strong commitment to achieving team goals. The performance criterion for team processes becomes:

TEAM PROCESSES: "The team achieves challenging goals in productivity and team function by strategic use of team resources, synergistic collaboration, decisions that add real value, and assessment-driven refinement of processes."

Solution Requirements. Solution requirements define achievement targets or specifications for a design project. They establish common understanding among team members and other key stakeholders regarding the needs and opportunities available through the project. Understanding of the problem in its technical, natural, logistical, and social dimensions is a prerequisite for a good solution ${ }^{24}$. Understanding the needs and perspectives of customers, business people, technological constraints, and the general public is vital to the production of quality products ${ }^{34}$. In a competitive global environment, a successful design solution must address stakeholder concerns about legal issues, intellectual property, cost, and attractiveness of a solution. Solution requirements evolve over time as a more complete definition of stakeholder needs and societal constraints is developed.

Performance factors for solution requirements are: voice of the customer ${ }^{35}$, voice of business, voice of technology, and voice of the people. Solution requirements must demonstrate understanding of these different perspectives or voices. Stated requirements must identify customers (users, clients, etc.), properly represent their needs, and establish metrics for 
achievement of these needs. The business voice requires knowing stakeholders with a financial interest, defining their issues, seeing connections between business and technical issues, and understanding time constraints for a solution to achieve business value. The technology voice sets limitations due to existing and anticipated states of the technology, identifies windows of opportunity among existing technologies, and addresses intellectual property issues. The voice of society defines paths that follow ethical practices, comply with standards and codes, protect the environment, and show responsibility with regard to societal impact.

Quality in solution requirements relies on validity of understanding needs and usefulness of the requirements for guiding solution development. The performance criterion for solution requirements becomes:

SOLUTION REQUIREMENTS: "Stated requirements reflect an in-depth understanding of customer needs, business issues, state of the technology, and societal concerns about the solution, while providing clear targets for the development of a valuable solution."

Solution Assets. Solution assets are the benefits accrued to stakeholders from the development of a design project solution. This may be seen in the client's ratings of the design product's quality and the client's overall satisfaction with the product. Product quality is defined by the product's ability to meet stated functional requirements, its feasibility for implementation, creativity and simplicity of the solution, and the overall impression it engenders ${ }^{11}$. Solutions should have real value to the customer, investors, users of the product, and society as a whole.

Performance criteria for solution assets focus on proof that the design solution is valuable: proof of performance, proof of profitability, proof of feasibility, and proof of impact. In summary, the solution should bring defensible benefits associated with performance in the eyes of customers, profitability for those making investments, feasibility to those producing the solution, and positive impact in the eyes of the public. Performance benefits include efficiency, ease of use, user safety, and effectiveness in achieving desired functionality. Profitability benefits include cost savings, revenue projections, market potential, competitive life, and economic risk. Feasibility benefits address the solution's potential for being produced, implemented, maintained, and delivered to users. Impact addresses the ways that the solution can impact public health and safety, enjoyment, values, and achievements of society in general.

Quality in the design solution is reflected by the satisfaction and value perceived by those receiving the solution and those affected by the use or existence of that solution. The performance criterion for solution assets becomes:

SOLUTION ASSETS: "Design solutions meet or exceed expectations of stakeholders by delivering proven value in desired functionality, economic benefits, implementation feasibility, and favorable impacts on society." 


\section{Model Application to Accreditation}

The conceptual model for design, although developed primarily for use in classroom assessment (focused on students as the beneficiaries), also offers value as an aid in program assessment (where engineering educators are the primary beneficiaries). As noted earlier, this model of design encompasses a range of types of outcomes, including several that traditionally have challenged those conducting assessments. The extent to which the conceptual model overlaps outcomes being assessed for program accreditation makes this model valuable, and therefore, encourages its adoption by engineering educators.

The four performance areas identified for the conceptual model of design are mapped to all of the ABET engineering criterion 3 outcomes in Table 3. For example, personal capacity can include abilities to apply math and science, solve problems, address ethical and professional responsibilities, engage in lifelong learning, and use engineering tools. Team processes span functioning on teams and forms of communication, as well as possible use of engineering techniques. Solution requirements should span the design of products, communication, impacts of solutions, and knowledge of contemporary issues affecting solutions. Solution assets encompass experimentation to prove value, design of products, forms of communication, and understanding solution impacts. This alignment with ABET outcomes demonstrates the value of the conceptual model as a basis for developing assessments that support program accreditation as well as student classroom assessment.

Table 3: Alignment of conceptual model with ABET engineering criteria outcomes

\begin{tabular}{|c|c|c|c|c|c|c|c|c|c|c|c|}
\hline & & & & $\mathbf{B E}$ & Cri & ion & Out & mes & & & \\
\hline Performance Areas & 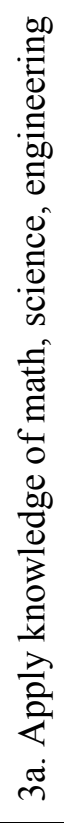 & 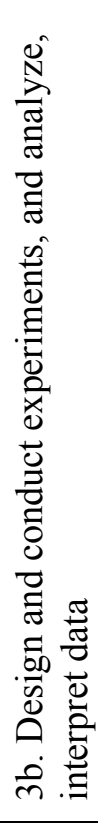 & 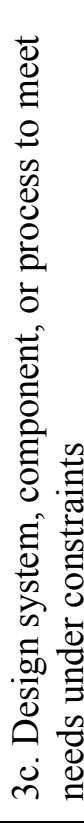 & 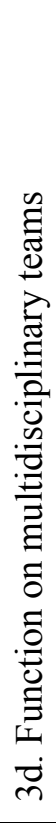 & 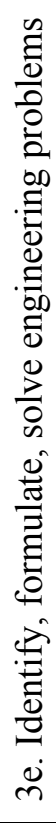 & 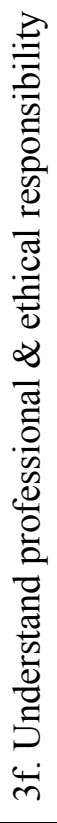 & 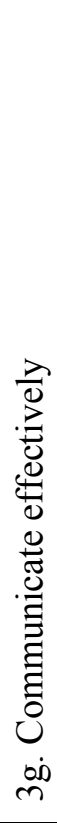 & 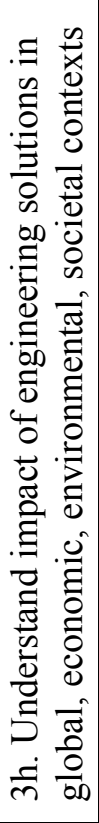 & 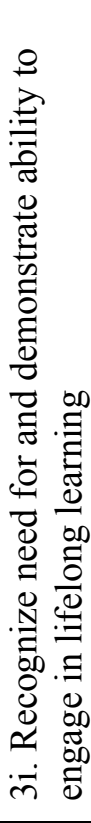 & 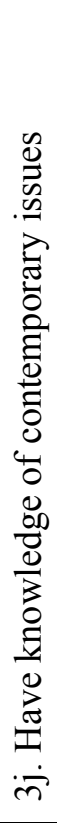 & 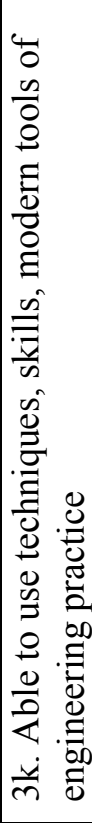 \\
\hline 1. Personal Capacity & $\mathbf{X}$ & & & & $\mathbf{X}$ & $\mathbf{X}$ & & & $\mathbf{X}$ & & $\mathbf{X}$ \\
\hline 2. Team Processes & & & & $\mathbf{X}$ & & & $\mathbf{X}$ & & & & \\
\hline 3. Solution Requirements & & & $\mathbf{X}$ & & & & $\mathbf{X}$ & $\mathbf{X}$ & & $\mathbf{X}$ & \\
\hline 4. Solution Assets & & $\mathbf{X}$ & $\mathbf{X}$ & & & & $\mathbf{X}$ & $\mathbf{X}$ & & & \\
\hline
\end{tabular}




\section{Summary and Conclusions}

The conceptual model for engineering design presented in this paper offers a valuable resource for improving design education, especially in capstone design courses. The model addresses design performance considered important to both learner development and solution development. Four performance areas - personal capacity, team processes, solution requirements, and solution assets - focus students' and educators' attentions on four aspects of design performance that together can represent achievements of design experts. Iterative and interactive aspects of the model describe the repeated use of an elementary design process to advance development and reveal ways in which each area of performance contributes to development of each other area. Therefore, this conceptual model presents a "scientifically credible understanding of ways learners represent knowledge and develop expertise in the domain" of design, which is required for developing assessments ${ }^{1}$.

In the context of capstone engineering design courses, this paper presents an integration of student learning and design product development attempted in such courses. These two developments work in parallel, are impacted by iterative use of the design process, and relate to the four areas of performance desired. Assessment of performance in each area may occur repeatedly during a project and should culminate at the completion of the project. The generality of the four performance areas makes the conceptual model applicable to widely varied courses found in different disciplines and institutions.

The authors are engaged in development of assessments for capstone engineering design courses based on this conceptual model for design. Separate assessments are targeted for each of the four performance areas identified in this paper. Successful development and testing of these assessments in a diverse set of institutions and disciplines offers potential for establishing valid measures of design performance as well as a basis for benchmarking performance within and across courses and institutions. The authors welcome feedback on the conceptual model to guide refinement that will achieve greatest value to engineering students and educators.

\section{References}

1. National Research Council (2001). Knowing What Students Know: The Science and Design of Educational Assessment. Washington, DC, National Academy Press.

2. Dym, C. L., A. M. Agogino, O. Eris, D. D. Frey, and L. J. Leifer. (2005). "Engineering Design Thinking, Teaching, and Learning." Journal of Engineering Education, 94(1): 103120.

3. Dutson, A. J., R. H. Todd, S. P. Magleby and C. D. Sorenson. (1997) "A Review of Literature on Teaching Design through Project-Oriented Capstone Courses," Journal of Engineering Education 76(1): 17-28.

4. McKenzie, L., M. Trevisan, D. Davis, and S. Beyerlein. (2004). "Capstone Design Courses and Assessment: A National Study.” American Society for Engineering Education Annual Conference, Salt Lake City, UT. 
5. ABET, (2006). "Criteria for Accrediting Engineering Programs," Baltimore, MD, www.abet.org.

6. Davis, D., M. Trevisan, L. McKenzie, S. Beyerlein, P. Daniels, T. Rutar, P. Thompson, and K. Gentili (2002). "Practices for Quality Implementation of the TIDEE 'Design Team Readiness Assessment'”. Annual Conference of the American Society for Engineering Education, Montreal, QE.

7. Atman, C. J. and K. M. Bursic (1998). "Verbal protocol analysis as a method to document engineering student design processes." Journal of Engineering Education 87(2): 121-132.

8. Cardella, M. E., C. J. Atman, R. S. Adams, and J. Turns. (2002). "Engineering Student Design Processes: Looking at Evaluation Practices Across Problems." American Society for Engineering Education Annual Conference and Exposition.

9. Mosborg, S., R. Adams, R. Kim, C. J. Atman, J. Turns, and M. Cardella. (2005). "Conceptions of the Engineering Design Process: An Expert Study of Advanced Practicing Professionals." American Society for Engineering Education Annual Conference, Portland, OR.

10. Sobek, D. K. (2002). "Use of Journals to Evaluate Student Design Processes.” American Society for Engineering Education Annual Conference, Montreal, Canada.

11. Sobek, D. K. I. and V. Jain (2004). "Two Instruments for Assessing Design Outcomes of Capstone Projects." Annual Conference of American Society for Engineering Education, Salt Lake City, UT.

12. Brackin, M. P. and J. Williams (2001). "Teaching and Assessing Team Skills in a Senior Level Design Course.” Annual Conference of American Society for Engineering Education, Albuquerque, NM.

13. Stiggins, R. J. (1997). Student-Centered Classroom Assessment. Upper Saddle River, NJ, Prentice-Hall.

14. Davis, D. C., S. W. Beyerlein, and I. T. Davis. (2006). "Deriving Design Course Learning Outcomes from a Professional Profile," International Journal of Engineering Education 22(1).

15. Dwarakanath, S. and K. M. Wallace (1995). "Decision-making in engineering design: Observations from design experiments." Journal of Engineering Education 6(3): 191-206.

16. Turns, J. (1997). "Learning Essays and the Reflective Learner: Supporting Assessment in Engineering Design Education." Frontiers in Education Conference, Pittsburgh, PA.

17. Adams, R. and J. Turns, and C. J. Atman. (2003). "Educating Effective Engineering Designers: The Role of Reflective Practice." Design Studies 24(3): 275-294.

18. Atman, C. J., J. R. Chimka, K. M. Bursic, and H. L. Nachtmann. (1999). "A Comparison of Freshman and Senior Engineering Design Processes." Design Studies 20(2): 131-152.

19. Adams, R. and C. J. Atman. (1999). "Cognitive Processes in Iterative Design Behavior." Frontiers in Education Conference, San Juan, Puerto Rico.

20. Ennis, C. W. and S. W. Gyeszly. (1991). "Protocol Analysis of the Engineering Systems Design Process." Research in Engineering Design 3: 15-22.

21. Baya, V. and L. J. Leifer. (1994). "A Study of the Information Handling Behavior of Designers During Conceptual Design." Design Theory and Methodology 68: 153-160.

22. Brinkman, G. W. and T. M. Geest (2003). "Assessment of Communication Competencies in Engineering Design Projects." Technical Communication Quarterly 12(1): 67-81.

23. Guindon, R. (1990). "Designing the Design Process: Exploiting Opportunistic Thoughts." Human-Computer Interaction 5: 305-344. 
24. Bogusch, L. L., J. Turns, and C. J. Atman. (2000). "Engineering Design Factors: How Broadly Do Students Define Problems?" Frontiers in Education Conference, vol. 2, S3A/7S3A12, Kansas City, MO.

25. Huba, M. E., and Jann E. Freed (2000). Learner-Centered Assessment on College Campuses. Needham Heights, MA: Allyn and Bacon.

26. Trevisan, M., D. Davis, S. Beyerlein, P. Thompson, and O. Harrison. (2006). "Evidence of Effective Formative Classroom Assessment in Capstone Engineering Design Literature." Annual Conference of American Society for Engineering Education, Chicago, IL.

27. Lumsdaine, E., M. Lumsdaine, and J. W. Shelnutt. (1999). Creative Problem Solving and Engineering Design. New York: McGraw-Hill.

28. TIDEE. "Transferable Integrated Design Engineering Education, www.tidee.wsu.edu.

29. National Academy of Engineering. (2005). The Engineer of 2020: Visions of Engineering in the New Century, Washington DC: National Academies Press.

30. Davis, D. C., S. W. Beyerlein, and I. T. Davis. (2005). "Development and Use of an Engineer Profile.” Annual Conference of American Society for Engineering Education, Portland, OR.

31. Gentili, K., J. Lyons, E. Davishahl, D. Davis, and S. Beyerlein. (2005). "Measuring AddedValue Using Team Design Skills and Growth Survey." Annual Conference of American Society for Engineering Education, Portland, OR.

32. Dominick, P. G., J. T. Demel, W. M. Lawbaugh, R. T. Freuler, G. L. Kinzel, and E. Fromm. (2001). Tools and Tactics of Design. John Wiley \& Sons.

33. McGourty, J. and K. P. De Meuse. (2001). The Team Developer: An Assessment and Skill Building Program. John Wiley \& Sons.

34. The Times 100. (2003). "Using Six Sigma Statistical Thinking to Improve Business Practices: A Cummins Case Study," http://www.sbtionline.com/files/Cumminscasestudy.pdf.

35. Otto, Kevin and Kristin Wood. (2001). Product Design: Techniques in Reverse Engineering and New Product Development, Upper Saddle River, NJ: Prentice-Hall, p. 112.

\section{Acknowledgements}

The authors acknowledge support from the National Science Foundation (Award: DUE 0404924) for support of this work. We also recognize our team of consultants who provided valuable perspectives and ideas for the development of the conceptual model for design. Consultants included: Robin Adams, Patricia Brackin, Isadore Davis, Louis Everett, Norman Fortenberry, and Durward Sobek. We are deeply saddened by the passing of Isadore T. Davis in November 2005; we will miss his friendship, energy, enthusiasm, and fresh ideas. 